\title{
Dictionaries and Their Users
}

Robert Lew*

Department of Lexicography and Lexicology, Adam Mickiewicz University in Poznań, Poznań, Poland

\begin{abstract}
It is only recently that dictionary users have become a central consideration in the design of dictionaries, and this focus has both stimulated and benefited from research into dictionary use. The present contribution reviews the major issues in dictionary design from the user perspective, taking stock of the relevant findings from user research, insofar as such research can assist lexicographers in producing improved lexical tools.
\end{abstract}

\section{Introduction}

Until fairly recently, dictionary users were not usually of central concern in the process of dictionary making, however strange it may sound today. Instead, the emphasis was largely on dictionary content and often on how to pack a lot into manageable physical space. The impulse for change is generally identified to have been Barnhart (1962), with attention turning to dictionary users. Gradually, dictionary makers have begun to recognize that dictionary users do not necessarily understand all the conventions implicated in the presentation of lexicographic data. Some of these conventions are motivated by space-saving considerations, others are carried over as part of the lexicographic tradition. With time, it has become increasingly clear that most people possess limited skills when it comes to using dictionaries, and this fact needs to guide decisions on how dictionaries are constructed and how lexicographic data should be presented.

Such thinking is in line with the view of dictionaries as tools primarily designed to assist human users in language-related tasks. Or, rather, this is a narrower or core view of dictionaries, which, to put things in a broader context, call for three brief qualifying statements.

First, in the days of natural language processing (or language engineering), it is no longer just humans that interact with dictionaries. There also exist dictionaries for machines, which function as lexical components of information systems of several types, such as translation engines, speech-to-text systems, search engines, and others.

Second, there exist specialized dictionaries focusing on the terminology of a particular domain of knowledge, which may be at several levels of generality or detail. For example, in order of narrowing focus, there are dictionaries of science and technology, chemistry, organic chemistry, gas chromatography, and water-purification technology. At each of these levels, dictionaries deal with (increasingly) specialized terminology, rather than with everyday language. In addition, there exist reference works with the word dictionary in the title that are not concerned with language as such, but may be compendia of knowledge in a particular domain, and in this noncentral sense dictionaries largely overlap with (thematic) encyclopedias.

Third, dictionaries are not always tools or plain utility products. Dictionaries may also carry symbolic meaning, by making a political statement as identity symbols, giving tangible testimony to the status or identity of a language-speaking community.

\footnotetext{
*Email: rlew@amu.edu.pl
} 
In what follows, I shall mainly focus on dictionaries in the narrower sense.

\section{Description}

There are several ways one can go about accommodating the needs of users in designing and perfecting dictionaries. One approach is to try to predict what the user might need by taking time to think about what they need to do, what they can do, and what skills they possess. Another is to ask the opinions of potential users. As with most tools, however, the real test usually comes from actual instances of users attempting to interact with the product, or its prototype, and noting the relative success of this interaction, plus any possible causes of failure. Such dictionary user studies try to answer a number of questions, and they do so by resorting to a variety of methodological approaches. Below I discuss a selection.

\section{Who Are Dictionary Users?}

One type of question that user studies ask is about the identity and characteristics of dictionary users. If dictionaries are to be designed with specific users in mind, then we need a picture of who those dictionary users are or are likely to be. This issue has several aspects. For instance, a publisher offering an online dictionary may be interested in knowing the characteristics of their typical users, including their demographics, languages spoken natively and nonnatively, their proficiency in those languages, their educational level, etc., with the overall aim of serving their particular needs better.

Conversely, specifying the (foreseen) characteristics of the target user at the planning stage helps in the design of dictionaries which do not yet exist, by equipping them with the lexicographic data that are likely to be expected and used, and presenting them in a way that takes account of the skill levels of the users, which includes language proficiency, metalinguistic awareness, and skills in navigating reference works. For example, the needs of a language teacher who uses a dictionary to mark written essays are far more sophisticated than those of a recreational reader of detective stories. The teacher will need, for instance, an exhaustive specification of verb complementation patterns as well as collocational choices, but these elements will normally be of little value in consulting a dictionary solely to look up the meaning of unknown words and expressions encountered in the text of a detective story. It is generally not a good idea to include in the dictionary more than the user is likely to need in whatever task they use the dictionary for, since irrelevant material makes it harder to locate the information that is of value.

\section{What Do Users Use Dictionaries for and How Do We Envisage the Purpose of Dictionaries?}

The example presented above highlights another central aspect of the relationship between the dictionary and its user. Dictionary use occurs in a particular context, and users reaching for dictionaries are typically immersed in some kind of activity. It may be helpful to distinguish in this regard a more general context, such as the setting of a language classroom, and a more specific type of activity, such as engaging in reading magazine articles, writing an essay, or completing written translation drills. Ideally, the offerings of a dictionary should be geared to the context and nature of such an activity. This was not a very realistic agenda in the days of print dictionaries, because excessively narrow specialization of a dictionary limits its opportunities for use and its target group, which, in turn, goes against the grain of the fundamental principles of commercial success. Since most dictionaries are commercial products, this consideration cannot be dismissed lightly.

Things take a different turn, however, when a dictionary is viewed - as now it should - as a digital product. In essence, such a dictionary can be made to be several different things in a single package, by equipping it with redundant data and selectively presenting only whatever data is relevant in the context of 
a particular situation of use. There are two broad paths that can be followed here: either the dictionary is controlled and adjusted by the user (customization), or it adapts itself to the needs of the user without their conscious intervention (De Schryver 2003, p. 189). The first mode requires conscious and skilled dictionary users, the second, a successful implementation of artificial intelligence based on a principled plan of what is needed under what circumstances. But what is needed under what circumstances?

\section{Typical Contexts of Dictionary Use}

Context of dictionary use is an under-researched area of dictionary use, not least because it is a challenging one due to the largely private nature of dictionary consultation. Investigating this aspect directly and systematically would call for near-continuous surveillance, which is at the same time ethically problematic, expensive, and technically difficult. If - and when - life-logging becomes more of a popular practice, it may offer an opportunity for investigating contexts of dictionary use directly. At present, researchers' choices in this regard are largely limited to indirect reporting by users. A recent study employing this methodology on a large sample is Müller-Spitzer (2014). She finds that the most common activities for which dictionary use is reported are, somewhat predictably: text production (usually writing), text reception (while reading), and text translation. Translation is basically - and simplifying somewhat - a combination of reception and production, of which one or the other may be more challenging, depending on the direction of the translation relative to the user's proficiency in the two languages involved and the difficulty as well as domain of the source text. Unlike translation, text reception and text production may be done in a monolingual context, when a text is being read or written in the dictionary user's native language. If this is the case, a monolingual dictionary will be appropriate. Text reception or production in the user's nonnative language, and any translation task, will bring into the equation an additional language (and at times more than one). In such contexts of use, bilingual dictionaries will become relevant, with the native language serving a function dependent on the nature of the activity.

For text reception, a dictionary with a large number of headwords arranged alphabetically will normally be most useful, since texts can potentially include any vocabulary items, including rare ones. The comprehensiveness requirement may be relaxed in the case of dictionaries for children and foreign language learners, insofar as these potential dictionary users are more likely to be exposed to texts written using a controlled vocabulary (such as textbooks, graded readers, or other learning materials). Lexicographic treatment in dictionaries for reception may be relatively shallow: enough to clarify the meaning. For native speakers of a language, a definition would be the most important element in the entry, perhaps accompanied by an illustration where a definition is unlikely to be sufficient (Hupka 1989; Ilson 1987), or, at times, the indication of special status, pragmatic constraints, or connotation. For reception in a foreign language, engaging the user's native language will do much to facilitate comprehension by capitalizing on the user's intuitive command of their native language (Varantola 2002). A native language equivalent is normally far easier to understand and process than a definition in the foreign language, however skillfully worded. This appears to be true even for very advanced learners of a language (Lew 2004). An equivalent is also much shorter and capable of conveying non-propositional features such as formality or register. In those cases where a satisfactory equivalent does not exist, a definition in either language remains an option.

For text production, generally a more modest coverage of vocabulary items will suffice, given that anyone's productive vocabulary is smaller than their receptive vocabulary, for native and nonnative speaker alike. By contrast, the lexicographic treatment should be more detailed than for text reception, allowing the dictionary user to construct natural phrases and sentences with the headword. To that end, the user will typically need guidance on syntactic patterns into which the headword enters, as well as collocates, preferably with examples of use to serve as a model for production. 
Before a word or phrase can be used in a sentence, however, it first needs to be identified in the dictionary as an appropriate lexical candidate for expressing the intended meaning. For this part, monolingual alphabetic dictionaries are ill-suited and thematically organized dictionaries or thesauri present particular access problems, as there is no single obvious way to classify concepts, ideas, or objects. Still, thesauri and dictionaries of synonyms remain the only option in monolingual contexts. For production in the nonnative language, a good bilingual dictionary going from the user's native language to the target language normally ensures the most direct route to finding the target language expressions, with the user's native language providing an effective entry index to the lexical system of another lesser-known language (Adamska-Sałaciak 2010; Lew and Adamska-Sałaciak 2015; Varantola 2002).

Having identified the candidate lexical item, the user may need a follow-up lookup in a monolingual dictionary or in an L2-L1 dictionary to find out how the word should be combined with other words (Atkins and Varantola 1997; Müller-Spitzer 2014). This second step is not needed if the first dictionary consulted is a quality bilingual learner's dictionary designed specifically for L2 production by speakers of L1. Such dictionaries already include a satisfactory coverage of collocational and colligational information as well as examples for L2 equivalents given at the L1 lemma, but such bilingual active dictionaries are expensive to make and are thus only available for a small minority of language pairs, of which the L2 is most usually English (Laufer and Levitzky-Aviad 2006; Lew and Adamska-Sałaciak 2015). If there are no sufficiently up-to-date or complete bilingual dictionaries, users have to rely more on monolingual resources for the target language, usually combining a bilingual lookup to identify candidate expression with a follow-up monolingual lookup to get the details needed for successful production. Native speakers of the less frequently spoken languages are at a particular disadvantage in this regard.

\section{Speakers of One Language as Users of Bilingual Dictionaries}

Bilingual dictionaries for production (active dictionaries) follow the recommendation of numerous experts (Adamska-Sałaciak 2010; Al-Kasimi 1984; Kromann et al. 1984; Svensén 1993), who have argued convincingly that bilingual dictionaries may and should be optimized for speakers of one language. Yet, until fairly recently, bilingual dictionaries meeting this condition had been vanishingly rare. Commercial considerations prevailed, with the prospects of being able to market and sell a particular bilingual dictionary to native speakers of two languages - rather than just one - being the decisive factor. In recent years, however, dictionaries designed for speakers of one of the two languages only (directional bilingual dictionaries) have become less of a rarity (Lew and Adamska-Sałaciak 2015).

\section{Defining Format}

In monolingual dictionaries, meaning explanation is by design restricted to the language of the headwords. This usually works reasonably well for native speakers of the language, but nonnative speaking users of the dictionary (such as language learners) may, and often do, experience problems understanding definitions couched in what, for them, is a foreign language. Mindful of this problem, English lexicographers had come up with the idea of vocabulary control (for an exhaustive discussion, see Cowie 1999). In the majority of leading British monolingual dictionaries for learners of English published today, definitions are written using a controlled list of vocabulary items, typically the 2,500-3,500 most common and useful - for users as well as lexicographers - words of English (though the number gets much higher once individual senses are counted, cf. De Schryver and Prinsloo 2011, p. 9). Such definitions are less likely to challenge language learners with unfamiliar items, which would need to be looked up again before the definition is understood. The price to pay for this, though, is quite heavy. Restrictions in the range of words allowed in definitions so imposed make it difficult, and often impossible, to convey finer subtleties of meaning, oftentimes resulting in similarly vague definitions for only partially synonymous items (Yamada 2013). The syntax may become more complex and the definitions get longer, as 
lexicographers struggle to paraphrase around words outside the allowed set (such as defining the noun lava without explicit reference to a volcano). Language learners are also exposed to collocations that are less than natural, as some of the more usual collocates lie outside the defining vocabulary. Despite these valid objections, there is some empirical evidence that definitions in English learners' dictionaries are easier to understand by learners (Grochocka 2008).

Of course, not all definitions in learners' dictionaries are made to the same recipe. A well-known innovation which has made quite an impact on other dictionaries was a systematic introduction by COBUILD1 of the full-sentence definition, which presents the defined lemma in a typical textual environment and then paraphrases the meaning of such an extended context, as in If you endeavour to do sth, you try very hard to do it (COBUILD1: 465). The rationale for this defining format is set out in Hanks (1987), and its limitations are considered in Rundell (2006). One might expect that the embedding of the headword in a typical environment would go some way toward helping learners to produce wellformed sentences, but in a recent systematic comparison (Chan 2013) of LDOCE5 and COBUILD6 entries, Hong Kong learners, who referred to the definition more than to any other entry component, rated COBUILD6 as less useful than LDOCE5 for sentence construction. Conversely, they found COBUILD6 relatively more useful than LDOCE5 for meaning determination (decoding). This is quite a surprising finding, given that COBUILD's full-sentence defining format appears to be optimized for sentence production through a presentation of the headword in a typical environment. Clearly, more research is needed on the matter, but we should also keep in mind that, whenever possible, including the users' native language will do much to ensure better comprehension of meaning explanation in a dictionary.

Another variation on the definition format which - although not an absolute innovation (Osselton 2007; Stein 2011) - enjoyed a period of popularity in several English learners' dictionaries around the 1990s and 2000 s is the single-clause when-definition. This format is used mainly for defining abstract nouns for which it is difficult to find a useful genus term, for example, when adultery is defined as "when you have sex with someone who is not your husband or wife." Defining by this type of clause introduced with when (or, less commonly, if or another wh-word) avoids the problem of having to supply an unhelpful general genus noun such as act or practice. However, this genus noun also conveys the information that the item defined is a noun, which appears to be largely lost in a when-definition. As a result, learners of English exposed to such definitions are more likely to interpret the definition as defining a verb (such as, in this case, "have sex") or an adjective (say, "immoral"), as shown in a series of user studies (Dziemianko and Lew 2006, 2013; Lew and Dziemianko 2006, 2012).

\section{Example Sentences}

In the late 1980s a lively debate was initiated among lexicographers about which types of examples served dictionary users better: those invented by the lexicographer or those derived from a corpus. Proponents of corpus-based examples argued that usage cannot be invented and pointed out the occasional artificiality of invented examples. The more traditionally minded lexicographers countered that examples from corpora are problematic because they have been torn out of their original textual context. A compromise position was that examples can be taken from a corpus but somewhat modified to repair the context dependence. As the debate continued, opinion shifted more and more in favor of corpus-based examples. The corpus side of the argument was no doubt largely helped by the steady increase in the size of available corpora. With smaller corpora, it was indeed often difficult to find fitting examples, but this became less of an excuse as corpora got bigger. The most recent user studies (Frankenberg-Garcia 2012, 2014) demonstrate that presenting dictionary users with three examples per sense is significantly more helpful than just a single example. Also, text comprehension and text production require rather different types of examples: text comprehension is best served with context-rich examples that elucidate the meaning, while text production requires examples that illustrate the combinatory properties of the lemma. This interesting 
finding presents a challenge to digital lexicography of the future: how to select the most useful examples (for a given use) from an extensive text corpus?

\section{User Interfaces for Digital Dictionaries}

The transition of dictionaries from paper to digital form raises questions of interface design for dictionaries as digital products. This is an area where the more traditional dictionary user studies find common ground with a more recent research tradition in the area of human-computer interaction: usability studies. Bank $(2010,2012)$ investigated the user experience of three online dictionaries with German and French (for a summary in English, see Heid 2011). One of the dictionaries subjected to the usability investigation was Base lexicale du français (BLF), a portal for learners of French designed to the specification of function-based lexicography (Verlinde 2010; Verlinde et al. 2010), where the user is first asked to specify the task that they intend to use the dictionary for. Disappointingly, Bank's study revealed that users of BLF experienced severe problems with the interface, performing much worse than in the case of more traditionally designed dictionaries.

Details of dictionary interface design were also addressed by Kaneta (2011), who tested two types of entry layout: traditional and layered ("folded") with the help of eye tracking. A layered interface seemed to prevent users from viewing example sentences, but this did not lead to inferior performance. In fact, for the bilingual entries, the layered interface may be calculated from the data supplied by Kaneta to be three times as likely to end in success compared with the traditional presentation. This difference is not significant ( $p=0.12$, Fisher exact probability test), but the sample was very small, limiting the power of the test.

Eye tracking was also used to assess user behavior with polysemous bilingual entries by Lew et al. (2013). The study found that sense-guiding elements do attract a lot of the users' attention, just as lexicographers would have hoped, and so do any elements appearing in bold type. Further, repeated exposure to the same equivalent can influence users' decisions in choosing the equivalent to use, to the point that they tend to ignore a contextually correct but isolated equivalent despite having seen it. Users appear to be swayed here by a sort of "majority vote," which leads the authors to recommend that bilingual dictionaries use target-equivalent structure (Jarošová 2000; Lew 2013) as more user-friendly (and economical, too). This study was done with dictionary page mock-ups modeled on the print version and presented on screen, but the findings have general relevance for the presentation of lexicographic data, also in digital media.

A recent study (Koplenig and Müller-Spitzer 2014) revisits the options considered in Kaneta (2011) with respect to organizing the different types of lexical information, in this case: grammatical information, paraphrase (definition), typical contexts (collocation and colligation), and sense relations (synonyms and others). The layered interface is called the "explorer view," the traditional interface the "print view," and two more are tested: a "panel view," where the four sections of the entry are laid out in four rectangular regions of the screen, and finally a "tabbed view." These four layout options were presented to users for evaluation. The tabbed interface was ranked highest, followed by the panel view, explorer view, and print view, in this sequence. The study was done using large screens, but the tabbed and explorer options also seem practical on small-screen devices such as smartphones. Neither of these has been utilized much in digital dictionaries. The tabbed view is particularly promising, given its familiarity from modern Web browsers. Users surveyed in Koplenig and Müller-Spitzer (2014) valued this option particularly for clarity and ease of navigation. 


\section{Future Prospects}

While it is fairly uncontroversial that people will continue to have lexical needs in natural communication as well as in more or less artificial learning contexts, it is much less certain that dictionaries will persist for much longer, at least in the form we know them today. Rather, it seems likely that dictionaries will increasingly become absorbed into more general digital tools designed to provide assistance with communication, expression, and information searching. Such tools are already becoming available in the form of writing assistants (Wanner et al. 2013).

\section{Acknowledgment}

This work was supported in part by the Polish National Science Centre (Narodowe Centrum Nauki), under grant DEC-2013/09/B/HS2/01125.

\section{References}

Adamska-Sałaciak, A. (2010). Why we need bilingual learners' dictionaries. In I. J. Kernerman \& P. Bogaards (Eds.), English learners' dictionaries at the DSNA 2009 (pp. 121-137). Tel Aviv: K Dictionaries.

Al-Kasimi, A. M. (1984). The interlingual/translation dictionary. In R. R. K. Hartmann (Ed.), Lexicography: Principles and practice (pp. 153-162). London: Academic.

Atkins, B. T. S., \& Varantola, K. (1997). Monitoring dictionary use. International Journal of Lexicography, 10(1), 1-45.

Bank, C. (2010). Die Usability von Online-Wörterbüchern und elektronischen Sprachportalen. (M.A.), Universität Hildesheim.

Bank, C. (2012). Die Usability von Online-Wörterbüchern und elektronischen Sprachportalen. Information - Wissenschaft \& Praxis, 63(6), 345-360.

Barnhart, C. L. (1962). Problems in editing commercial monolingual dictionaries. In F. W. Householder \& S. Saporta (Eds.), Problems in lexicography (pp. 161-181). Bloomington: Indiana University.

Chan, A. Y. W. (2013). Using LDOCE5 and COBUILD6 for meaning determination and sentence construction: What do learners prefer? International Journal of Lexicography, 27(1), 25-53.

Cowie, A. P. (1999). English dictionaries for foreign learners: A history. Oxford: Clarendon.

De Schryver, G.-M. (2003). Lexicographers' dreams in the electronic-dictionary age. International Journal of Lexicography, 16(2), 143-199.

De Schryver, G.-M., \& Prinsloo, D. J. (2011). Do dictionaries define on the level of their target users? A case study for three Dutch dictionaries. International Journal of Lexicography, 24(1), 5-28.

Dziemianko, A., \& Lew, R. (2006). When you are explaining the meaning of a word: The effect of abstract noun definition format on syntactic class identification. In E. Corino, C. Marello, \& C. Onesti (Eds.), Atti del XII Congresso di Lessicografia, Torino, 6-9 settembre 2006 (Vol. 2, pp. 857-863). Allessandria: Edizioni dell'Orso.

Dziemianko, A., \& Lew, R. (2013). When-definitions revisited. International Journal of Lexicography, 26(2), 154-175.

Frankenberg-Garcia, A. (2012). Learners' use of corpus examples. International Journal of Lexicography, 25(3), 273-296. 
Frankenberg-Garcia, A. (2014). The use of corpus examples for language comprehension and production. ReCALL, 26(2), 128-146.

Grochocka, M. (2008). The usefulness of the definitions of abstract nouns in OALD7 and NODE. Poznań Studies in Contemporary Linguistics, 44(4), 469-501.

Hanks, P. (1987). Definitions and explanations. In J. Sinclair (Ed.), Looking up: An account of the COBUILD project in lexical computing (pp. 116-136). London/Glasgow: Collins.

Heid, U. (2011). Electronic dictionaries as tools: Towards an assessment of usability. In P. A. FuertesOlivera \& H. Bergenholtz (Eds.), e-lexicography: The internet, digital initiatives and lexicography. London: Continuum.

Hupka, W. (1989). Wort und Bild. Die Illustrationen in Wörterbüchern und Enzyklopädien. Tübingen: Niemeyer.

Ilson, R. F. (1987). Illustrations in dictionaries. In A. P. Cowie (Ed.), The dictionary and the language learner (pp. 193-212). Tübingen: Niemeyer.

Jarošová, A. (2000). Problems of semantic subdivisions in bilingual dictionary entries. International Journal of Lexicography, 13(1), 12-28.

Kaneta, T. (2011). Folded or unfolded: Eye-tracking analysis of L2 learners' reference behavior with different types of dictionary. In K. Akasu \& S. Uchida (Eds.), ASIALEX2011 Proceedings. Lexicography: Theoretical and practical perspectives (pp. 219-224). Kyoto: Asian Association for Lexicography.

Koplenig, A., \& Müller-Spitzer, C. (2014). Questions of design. In C. Müller-Spitzer (Ed.), Using online dictionaries (pp. 189-204). Berlin: Walter de Gruyter.

Kromann, H.-P., Riiber, T., \& Rosbach, P. (1984). 'Active' and 'passive' bilingual dictionaries: The Ščerba concept reconsidered. In R. R. K. Hartmann (Ed.), LEXeter '83 proceedings. Papers from the International Conference on Lexicography at Exeter, 9-12 September, 1983 (pp. 207-215). Tübingen: Niemeyer.

Laufer, B., \& Levitzky-Aviad, T. (2006). Examining the effectiveness of 'bilingual dictionary plus' - A dictionary for production in a foreign language. International Journal of Lexicography, $19(2), 135-155$.

Lew, R. (2004). Which dictionary for whom? Receptive use of bilingual, monolingual and semi-bilingual dictionaries by Polish learners of English. Poznań: Motivex.

Lew, R. (2013). Identifying, ordering and defining senses. In H. Jackson (Ed.), The Bloomsbury companion to lexicography (pp. 284-302). London: Bloomsbury Publishing.

Lew, R., \& Adamska-Sałaciak, A. (2015). A case for bilingual learners' dictionaries. ELT Journal, 69(1), 47-57.

Lew, R., \& Dziemianko, A. (2006). Non-standard dictionary definitions: What they cannot tell native speakers of Polish. Cadernos de Traduçao, 18, 275-294.

Lew, R., \& Dziemianko, A. (2012). Single-clause when-definitions: Take three. In R. V. Fjeld \& J. M. Torjusen (Eds.), Proceedings of the 15th EURALEX International Congress (pp. 997-1002). Oslo: Department of Linguistics and Scandinavian Studies, University of Oslo.

Lew, R., Grzelak, M., \& Leszkowicz, M. (2013). How dictionary users choose senses in bilingual dictionary entries: An eye-tracking study. Lexikos, 23, 228-254.

Müller-Spitzer, C. (2014). Empirical data on contexts of dictionary use. In C. Müller-Spitzer (Ed.), Using online dictionaries (pp. 85-126). Berlin: Walter de Gruyter.

Osselton, N. E. (2007). Innovation and continuity in english learners' dictionaries: The single-clause when-definition. International Journal of Lexicography, 20(4), 393-399. 
Rundell, M. (2006). More than one way to skin a cat: Why full-sentence definitions have not been universally adopted. In E. Corino, C. Marello, \& C. Onesti (Eds.), Atti del XII Congresso di Lessicografia, Torino, 6-9 settembre 2006 (Vol. 1, pp. 323-337). Allessandria: Edizioni dell'Orso.

Stein, G. (2011). The linking of lemma to gloss in Elyot's Dictionary (1538). In O. Timofeeva \& T. Säily (Eds.), Words in dictionaries and history. Essays in honour of R.W. McConchie (pp. 55-79). Amsterdam: John Benjamins.

Svensén, B. (1993). Practical lexicography. Principles and methods of dictionary-making. Oxford: Oxford University Press.

Varantola, K. (2002). Use and usability of dictionaries: Common sense and context sensibility? In M.-H. Corréard (Ed.), Lexicography and natural language processing. A festschrift in honour of B.T.S. Atkins (pp. 30-44). Grenoble: EURALEX.

Verlinde, S. (2010). The base lexicale du français: A multi-purpose lexicographic tool. In S. Granger \& M. Paquot (Eds.), eLexicography in the 21st century: New challenges, new applications (pp. 335-342). Louvain-la-Neuve: Cahiers du CENTAL.

Verlinde, S., Leroyer, P., \& Binon, J. (2010). Search and you will find. From stand-alone lexicographic tools to user driven task and problem-oriented multifunctional leximats. International Journal of Lexicography, 23(1), 1-17.

Wanner, L., Verlinde, S., \& Ramos, M. A. (2013). Writing assistants and automatic lexical error correction: Word combinatorics. In I. Kosem, J. Kallas, P. Gantar, S. Krek, M. Langemets \& M. Tuulik (Eds.), Electronic lexicography in the 21st century: Thinking outside the paper. Proceedings of the eLex 2013 conference, 17-19 October 2013, Tallinn, Estonia. Ljubljana/Tallinn: Trojina, Institute for Applied Slovene Studies/Eesti Keele Instituut.

Yamada, S. (2013). Monolingual learners' dictionaries - Where now? In H. Jackson (Ed.), The Bloomsbury companion to lexicography (pp. 188-212). London: Bloomsbury Publishing.

\section{Dictionaries}

[BLF] Base lexicale du français. http://ilt.kuleuven.be/blf/.

[LDOCE5] Mayor, M. (2009). Longman Dictionary of Contemporary English (5th ed.). Harlow: Pearson Education.

[COBUILD1] Sinclair, J., \& Hanks, P. (Eds.). (1987). Collins COBUILD English Language Dictionary. London: Collins.

[COBUILD6] Sinclair, J., et al. (Eds.). (2009). Collins COBUILD Advanced Dictionary (6th ed.). London: HarperCollins. 